\title{
Resíduos de antimicrobianos em leite bovino: fonte de contaminação, impactos e controle
}

\author{
Antimicrobial residues in dairy milk: contamination source, impacts and control
}

\section{Marcella Nunes Pereira* e Vildes Maria Scussel}

\section{RESUMO}

O leite é um alimento rico em sua composição e amplamente consumido. Nele, os consumidores buscam nutrientes para uma vida saudável, acreditando que seja livre de contaminantes e resíduos químicos. Porém, sabe-se que a presença de resíduos de substâncias químicas é um achado comum no leite, dentre elas os antimicrobianos de tratamentos nos quais não foram respeitados o período de carência. Equipamentos contaminados, ordenha incorreta e adulteração de leite com baixa qualidade higiênicosanitária também levam à sua contaminação com resíduos antimicrobianos. Tais substâncias interferem na indústria de laticínios, gerando perdas e interferindo em análises laboratoriais de rotina nas indústrias, como testes de fosfatase, peroxidase e redutase. No entanto, o maior risco é para a saúde humana, na qual pode causar diversos danos como processos de hipersensibilidade, teratogênese, alteração da microbiota intestinal, podendo prejudicar sua ação gastromucoprotetora, além de propiciar a seleção de populações de bactérias altamente resistentes. Este trabalho teve por objetivo levantar dados bibliográficos sobre como acontece a contaminação do leite com os antibióticos, qual seu impacto na sociedade e como controlar este problema.

PALAVRAS-CHAVE: contaminação, leite, resíduo.

\section{ABSTRACT}

Milk is a food rich in its composition and widely consumed. In it, consumers seek nutrients for a healthy life, believing it to be free of contaminants and chemical residues. However, it is known that the presence of chemical waste is a common finding in milk, among them antimicrobial treatments in which the withdrawal period was not respected. Contaminated equipment, improper milking and milk adulteration and low sanitary conditions also lead to contamination with antimicrobial residue. These substances interfere in the dairy industry, generating losses and interfering with the routine laboratory tests in industries, such as phosphatase, peroxidase and reductase tests. However, the greatest risk is to human health, which can cause extensive deleterious effects such as hipersensivity processes, teratogenesis, changes in intestinal microbiota and may harm your gastromucoprotector action, as well as providing a selection of populations of highly resistant bacteria. This study aimed to raise bibliographic data about how milk contamination with antibiotics happens, their impact on society and how to control this problem.

KEYWORDS: contamination, milk, residue.

\section{INTRODUÇÃO}

No ano de 1532 teve início a pecuária de leite no Brasil, quando foram trazidos os primeiros bovinos da Europa para a Vila de São Vicente, no litoral paulista. Por muito tempo a atividade se desenvolveu a passos lentos, até que, ao final dos anos 60 e principalmente a partir da década de 80 , o setor obteve grande dinamismo, apresentando progressos em pouco tempo (RUBEZ 2003).

O Brasil é detentor do segundo maior rebanho bovino, sendo o quarto maior produtor mundial de leite com volume de produção de 6,1 bilhões de litros de leite cru entregues a laticínios no primeiro trimestre de 2015 (IBGE 2015). Com todo esse crescimento, a preocupação com a qualidade deste leite torna-se cada vez maior. Os bovinocultores têm a responsabilidade de ofertar matéria-prima dentro dos padrões exigidos pelos órgãos regulatórios, indústrias e até mesmo consumidores, evitando o comprometimento de um alimento seguro por meio de perigos biológicos, físicos e químicos (BRITO \& LANGE 2005, COSTA et al. 2009, VIEIRA 2010, USDA 2011).

Universidade Federal de Santa Catarina, Florianópolis, SC, Brasil.

*Autor para correspondência <marcella.mnp@gmail.com> 
Um dos resíduos químicos mais comuns de serem encontrados no leite são os de medicamentos veterinários (DÜRR 2004). Este trabalho traz uma breve abordagem sobre a presença de agentes antimicrobianos no leite, englobando a sua fonte de contaminação, os impactos para indústria e saúde humana, bem como as formas de controle da presença destes resíduos no produto.

\section{DESENVOLVIMENTO}

Entende-se por leite, sem outra especificação, o produto oriundo da ordenha completa e ininterrupta, em condições de higiene, de vacas sadias, bem alimentadas e descansadas (BRASIL 2002). É o mais valioso alimento natural para todos os mamíferos, principalmente lactantes, crianças e animais em desenvolvimento, pelo seu alto e completo teor nutritivo (BARROS et al. 2001).

$O$ leite de origem bovina consiste em um fluido formado por diversos nutrientes previamente sintetizados na glândula mamária a partir de precursores derivados da alimentação e metabolismo dos animais. É uma emulsão dos glóbulos de gordura e micelas de caseína (compostas por caseína, cálcio e fósforo) em dispersão coloidal suspensas em fase aquosa que contém moléculas de lactose, proteínas do soro do leite e alguns minerais solubilizados. $\mathrm{Na}$ fase suspensa, ainda se encontram os leucócitos. Composto quimicamente de $87 \%$ de água, 3,8\% de gordura, 3,5\% de proteínas, 4,9\% de lactose e $0,8 \%$ de sais, também apresenta pigmentos como riboflavina e caroteno, enzimas como lactoperoxidase, lipase, catalase, fosfatase e redutase; e vitaminas lipossolúveis e hidrossolúveis. É rico em proteínas de alto valor biológico, possui alta digestibilidade de gorduras, além de exercer influência reguladora sobre a microbiota bacteriana do trato intestinal (VEISSEYRE 1998).

\section{Inocuidade do leite}

Alimentos produzidos de maneira inócua cada vez mais têm se tornado o centro das atenções, visto a crescente busca por uma alimentação saudável e qualidade de vida. Além disso, é notória a conscientização das pessoas em relação ao seu direito de consumir produtos seguros à saúde.

O leite é um alimento consumido diariamente e, desta maneira, deve apresentar condições sanitárias apropriadas, sendo isento de qualquer forma de contaminação ou substância estranha (COVA 1984). Sua qualidade higiênica é influenciada por diversos fatores, como o estado sanitário do rebanho, manejo dos animais e equipamentos durante a ordenha, e a presença de microrganismos, resíduos de produtos de uso veterinário e odores estranhos (BRITO \& BRITO 1997, DÜRR 2004). Por ser composto de nutrientes facilmente assimiláveis, o leite é um excelente meio de cultura para a maioria dos microrganismos. No entanto, é proibida a presença de inibidores ou substâncias para aumentar sua capacidade de conservação. Os antimicrobianos podem ser incorporados ao leite de modo acidental pelo tratamento medicamentoso sem respeitar o período de carência, ou ainda como adulterantes para evitar a proliferação de microbiota contaminante ou deteriorante (SILVA et al. 2013).

O leite contaminado por resíduos ilícitos ou acima do limite máximo de resíduos (LMR) estabelecido legalmente para antimicrobianos é considerado adulterado e impróprio para o consumo, representando danos à saúde humana e tecnológicos para a indústria de laticínios, além de rejeição da imagem da empresa pelo consumidor (FOLLY \& MACHADO 2001). A impropriedade para o consumo acontece quando se ultrapassa o LMR determinado no Brasil pelo Ministério da Agricultura, Pecuária e Abastecimento, o MAPA (BRASIL 2011). Poucos são os países que dispõem de estatísticas abrangentes a respeito das quantidades de produtos de uso veterinário utilizados nas criações animais (DÍAZ-CRUZ \& BARCELÓ 2007), mas estima-se que mais de 70\% desses compostos sejam agentes antimicrobianos (THIELE-BRUHN 2003). No Brasil, atualmente é autorizado pelo MAPA o uso de aproximadamente 15 compostos antimicrobianos como aditivos na alimentação animal e outros 50 para fins terapêuticos (PALERMO-NETO \& ALMEIDA 2014).

\section{O uso de antimicrobianos}

De acordo com SPINOSA \& TÁRRAGA (2014), os antimicrobianos são substâncias químicas sintetizadas por microrganismos ou seus equivalentes in vitro, com a capacidade de, em pequenas quantidades, inibir o crescimento (bacteriostático, fungiostático) ou destruir (bactericida, fungicida) os microrganismos patogênicos.

A aplicação indiscriminada ou de maneira incorreta de produtos de uso veterinário em vacas tem gerado problemas ao homem pela presença de seus resíduos nos laticínios. Este fato tem trazido grande 
preocupação no que se refere ao seu uso, já que pode gerar organismos resistentes (ANTUNES 1985).

Os antimicrobianos são utilizados com objetivos mais amplos na veterinária do que tradicionalmente são usados na medicina humana. No emprego de antibioticoterapia específica, por exemplo, utilizase o medicamento como terapêutico e profilático, mas também há o uso metafilático e como aditivos zootécnicos (promotores de crescimento) (SPINOSA \& TÁRRAGA 2014). No caso da bovinocultura de leite, a terapêutica é a utilização do antimicrobiano em um animal ou rebanho que apresente doença infecciosa, a fim de controlar o agente com o princípio ativo ao qual ele seja sensível, como em casos de mastite e metrite. A profilaxia é a prevenção contra uma possível infecção como, por exemplo, em cirurgias ou ainda em vacas no período de secagem do leite. O uso metafilático é o chamado tratamento de animais de contato, ou seja, quando há alguns animais doentes, se utiliza a antibioticoterapia no rebanho inteiro para evitar a disseminação do agente. Por fim, o uso como aditivo tem o objetivo de reduzir a mortalidade, melhorar o crescimento e a conversão alimentar, no entanto, tem sido bastante contestado por promover resistência bacteriana (OLIVEIRA et al. 2005), sendo alguns princípios proibidos para esta finalidade.

Para PALERMO-NETO \& ALMEIDA (2014), os antimicrobianos mais comumente utilizados no tratamento de bovinos com mastite podem ser divididos em oito principais classes (Figura 1): beta-lactâmicos, aminoglicosídeos, lincosamidas, macrolídeos, polimixinas, quinolonas, sulfas e tetraciclinas (Tabela 1).

O tratamento com antimicrobianos é necessário, sendo importante para sanidade animal, mas também para saúde pública, pela prevenção de zoonoses ou de doenças veiculadas por alimentos. Entretanto devese levar em conta as recomendações para seu uso, assim como todas as substâncias químicas. A terapia começa com a escolha correta do medicamento, que possua o princípio ativo ao qual o agente infeccioso seja sensível, sendo sempre prescrito por um médico veterinário e com correta administração ao animal.

\section{Fontes de contaminação do leite bovino com resíduos de antimicrobianos}

O Codex Alimentarius denomina resíduo de medicamentos veterinários a fração da droga administrada, seus metabólitos, produtos de conversão ou reação e impurezas que permanecem no alimento originário de animais tratados (SILVA et al. 2013).

O maior responsável pelos resíduos antimicrobianos no leite é o tratamento para mastite, que é feito pela aplicação do produto de uso veterinário pela via intramamária. Mesmo se a aplicação for realizada em apenas um dos quartos mamários, todos apresentarão resíduos, pois há absorção desta, que pela passagem da corrente sanguínea, contamina todo o produto (SILVA et al. 2013).

A antibioticoterapia local na glândula mamária é o maior problema da presença de resíduos no leite, pois a carga de princípio ativo é muito mais elevada. No entanto, o uso sistêmico também pode levar à contaminação do leite com resíduos, pois a região da glândula mamária é extremamente vascularizada (BACHA \& BACHA 2000, FRANDSON et al. 2014) e o leite é produzido a partir de elementos que passam do sangue para as células especializadas. Com esta permeabilidade também passam produtos de uso veterinário administrados ao animal (BRITO \& LANGE 2005).

Os animais de produção submetidos à terapia com antimicrobianos devem receber atenção do seu manipulador, de maneira a impedir que os resíduos da substância química utilizada (que fisiologicamente chega aos tecidos e, consequentemente, produtos de origem animal) atinjam a espécie humana e levem a ações deletérias. Para isso, os produtores e tratadores dos animais devem respeitar o período de carência. Este consiste em um espaço de tempo necessário para que o organismo metabolize e elimine o resíduo de preocupação toxicológica até concentrações seguras.

De acordo com COSTA (1996), a dose, via de administração, a composição utilizada e a solubilidade interferem na permanência dos resíduos de antimicrobianos no leite. Há também uma variabilidade conforme o produto lácteo em questão.

RAIA JR (2001) em estudo realizado no estado de São Paulo em vacas tratadas por via intramamária e sistêmica, verificou resíduos de substâncias antimicrobianas no leite por um período de tempo superior ao tempo de carência recomendado na bula. A persistência dos resíduos no leite pode ainda ser aumentada pela presença de processo inflamatório na glândula mamária.

JONES \& SEYMOUR (1988) apontam como causas para que se constatem resíduos de antimicrobianos no leite: tratamentos aleatórios, problemas ou falhas na identificação dos animais 


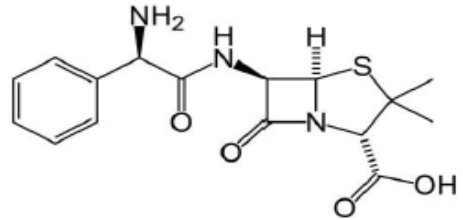

$\beta$-Lactâmicos: Ampicilina

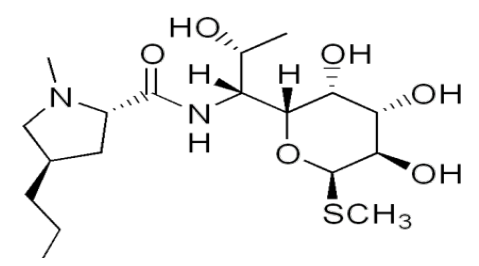

Lincosamidas: Lincomicina

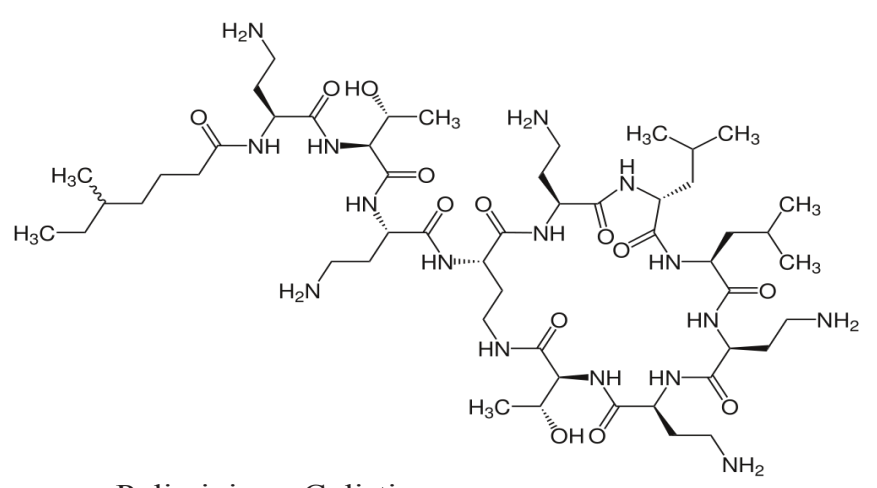

Polimixinas: Colistina<smiles>Nc1ccc(S(=O)(=O)Nc2ncccn2)cc1</smiles>

Sulfas: Sulfadiazina

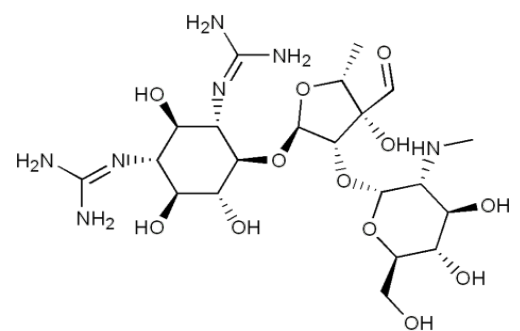

Aminoglicosídeos: Estreptomicina

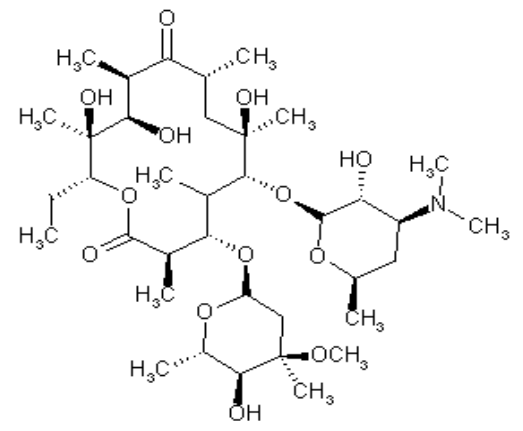

Macrolídeos: Eritromicina<smiles>CN1CCN(c2cc3c(cc2F)c(=O)c(C(=O)O)cn3C2CC2)CC1</smiles>

Quinolonas: Enrofloxacina<smiles>CN(C)[C@H]1C(O)=C(C(N)=O)C(=O)[C@]2(O)C(=O)C3=C(O)c4c(O)cccc4[C@@H](O)[C@H]3[C@H](O)[C@]12C</smiles>

Tetraciclinas: Oxitetraciclina

Figura 1 - Estrutura química de alguns antibióticos usados no tratamento de mastite bovina.

Figure 1 - Chemical structure of some antibiotics used in the treatment of bovine mastitis.

tratados, ausência de separação de vacas em tratamento no momento da ordenha, uso de dosagens múltiplas, uso de dosagem acima da recomendada, falhas na observação ou não cumprimento dos períodos de carência dos antimicrobianos administrados, uso de medicamentos por períodos muito prolongados ou excessivos, uso de medicamentos com períodos de excreção prolongados e mistura acidental de leite não contaminado com leite contaminado.

A higienização de equipamentos e dos utensílios da indústria e a adição intencional de substâncias químicas para encobrir a deficiência na qualidade higiênica do leite, visando inibir o crescimento bacteriano e aumentar seu tempo de vida útil também são causas de contaminação do leite (GUSTAFSON 1986, BORGES et al. 2000).

O fato de, mesmo com todo esse conhecimento, ainda haver a presença de resíduos no leite indica manejo indevido da antibioticoterapia em vacas em lactação e má qualidade higiênico-sanitária do produto comercializado.

A Organização Mundial de Saúde (OMS) faz recomendações periodicamente com a finalidade de alertar e enfrentar este problema através da imposição de normas de utilização de aditivos em geral e sugestão de práticas na tecnologia de alimentos e na Medicina Veterinária aos governos e autoridades competentes dos países. Nações como Estados Unidos, França, 
Tabela 1 - Principais Antimicrobianos utilizados no tratamento de mastite bovina.

Table 1 - Main antimicrobials used in the treatment of bovine mastitis.

\begin{tabular}{|c|c|c|c|}
\hline Grupo Antimicrobiano & Estrutura & $\begin{array}{l}\text { Espectro de } \\
\text { Ação }\end{array}$ & Modo de Ação \\
\hline $\begin{array}{l}\text { Beta-Lactâmicos } \\
\text { (Penicilinas e } \\
\text { Cefalosporinas) }\end{array}$ & $\begin{array}{l}\text { Penicilinas: derivam do } \\
\text { ácido 6-amino- } \\
\text { penicilinâmico. } \\
\text { Cefalosporinas: } \\
\text { provêm do ácido 7- } \\
\text { amino- } \\
\text { cefalosporinâmico }\end{array}$ & GRAM (+) & $\begin{array}{l}\text { Impedimento da formação da } \\
\text { parede celular das bactérias }\end{array}$ \\
\hline Aminoglicosídeos & $\begin{array}{l}\text { Núcleo de hexose } \\
\text { ligado à } \\
\text { aminoaçúcares por } \\
\text { ligações glicosídicas }\end{array}$ & $\begin{array}{c}\text { GRAM (-) e } \\
\text { Staphylococcus } \\
\text { spp. }\end{array}$ & $\begin{array}{l}\text { Ligação à porção } 30 \mathrm{~S} \text { do } \\
\text { ribossomo, interferindo na } \\
\text { síntese protéica bacteriana, } \\
\text { formando proteínas defeituosas }\end{array}$ \\
\hline Lincosamidas & $\begin{array}{l}\text { Monoglicosídeos } \\
\text { ligados a um } \\
\text { aminoácido }\end{array}$ & GRAM (+) & $\begin{array}{l}\text { Ligação à subunidade } 50 \mathrm{~S} \text { dos } \\
\text { ribossomos, inibindo a síntese } \\
\text { protéica }\end{array}$ \\
\hline Macrolídeos & Anel Lactônico & GRAM (+) & $\begin{array}{c}\text { Translocação do RNAt na } \\
\text { subunidade } 50 \mathrm{~S} \text { do ribossomo } \\
\text { impedindo a síntese protéica } \\
\text { bacteriana }\end{array}$ \\
\hline Polimixinas & Polipeptídico & GRAM (-) & $\begin{array}{c}\text { Alteram a permeabilidade da } \\
\text { membrana da célula } \\
\text { bacteriana, levando à sua } \\
\text { morte }\end{array}$ \\
\hline Quinolonas & Anel 4-quinolona & GRAM (+) e (-) & $\begin{array}{c}\text { Inibe a DNA girase bacteriana, } \\
\text { impedindo o enrolamento da } \\
\text { hélice de DNA }\end{array}$ \\
\hline Sulfas & $\begin{array}{c}\text { Análogas e } \\
\text { antagonistas } \\
\text { competitivas do } \\
\text { ácido para- } \\
\text { aminobenzóico } \\
\text { (PABA) }\end{array}$ & $\begin{array}{c}\text { GRAM (+) e } \\
\text { algumas GRAM (-) }\end{array}$ & $\begin{array}{c}\text { Impede a utilização do PABA } \\
\text { na síntese do ácido fólico pelas } \\
\text { bactérias }\end{array}$ \\
\hline Tetraciclinas & Quatro anéis & GRAM (+) e (-) & $\begin{array}{l}\text { Ligação à subunidade 30S dos } \\
\text { ribossomos, não permitindo } \\
\text { que o RNA transportador se } \\
\text { ligue a ele, inibindo assim a } \\
\text { síntese protéica }\end{array}$ \\
\hline
\end{tabular}

Fonte: ARAÚJO (2010), SPINOSA et al. (2014).

Dinamarca e Inglaterra possuem um constante controle de resíduos antibióticos no leite normatizado por legislações rígidas e campanhas educacionais focadas na conscientização do produtor (FAGUNDES 1981). A França, por exemplo, adotou a proibição da utilização de antimicrobianos de indicação médica humana para tratamento de enfermidades animais e em alimentos (BARROS et al. 2001).

No Brasil, a lei máxima no que diz respeito a produtos de origem animal, o RIISPOA (Regulamento de Inspeção Industrial e Sanitária de Produtos de Origem Animal), Artigo 514, em seu parágrafo único, institui que é proibido o uso de substâncias químicas na conservação do leite (BRASIL 1980). Porém, diversos estudos realizados no país apontam o uso abusivo de substâncias estranhas tais como antibióticos, detergentes e saneantes (ALMEIDA et al. 2003). Já para animais que necessitaram ser submetidos a tratamento, a Portaria do Ministério da Agricultura $\mathrm{N}^{\circ} 005$ de 24 de abril de 1980 estipula um prazo mínimo de 72 horas para o aproveitamento do leite destas vacas. Porém, o período de eliminação do medicamento depende da via de inoculação, dosagem, estado fisiológico da glândula mamária e a classe de 
antibiótico utilizada, podendo chegar até 141 horas (FAGUNDES 1978).

O MAPA (BRASIL 2002) não permite o envio de leite a Postos de Refrigeração ou estabelecimentos industriais, quando este produto provir de animais submetidos a tratamento com produtos de uso veterinário em geral, passíveis de eliminação pelo leite, motivo pelo qual devem ser afastados da produção pelo período recomendado pelo fabricante do medicamento, de forma a assegurar que os resíduos da droga não sejam superiores aos níveis fixados em normas específicas.

Os riscos à saúde humana representados pela exposição direta aos resíduos de antimicrobianos em alimentos de origem animal têm chamado a atenção dos órgãos regulamentadores e de pesquisa, que passaram a considerar os valores de Ingestões Diárias Aceitáveis (IDA) e Limites Máximos de Resíduos (LMR) estabelecidos para esses produtos (PALERMO-NETO 2007, PALERMO-NETO \& ALMEIDA 2014).

\section{Legislações e o estabelecimento de LMR}

Com o intuito de garantir a segurança do consumidor, organizações internacionais envolvidas com a saúde pública, como o JECFA - Comitê para Aditivos Alimentares da Organização das Nações Unidas para a Alimentação e a Agricultura (FAO)/ OMS e o FDA (Food and Drug Administration) dos Estados Unidos, estabeleceram diretrizes a fim de criar os LMR, determinados a partir de estudos toxicológicos, de curto e médio prazo, realizados em animais de laboratórios, microrganismos e genomas celulares. Este limite é definido como a concentração máxima de resíduo resultante do uso de medicamento veterinário, expresso em parte por milhão (ppm) ou parte por bilhão (ppb), que é o valor legalmente permitido, ou reconhecido, como aceitável no alimento, sendo estabelecido para cada princípio ativo aprovado para uso em animal produtor de alimento, sendo o valor de limite máximo de resíduo correlacionável ao IDA obtido a partir de ensaios com animais avaliando-se a toxicidade, teratogenicidade e carcinogenicidade desses aditivos não intencionais (KISER 1984, MITCHELL et al. 1998). A Tabela 2 mostra os LMR estabelecidos por alguns países.

Inicialmente, com a ausência de um programa próprio para os medicamentos veterinários no Brasil, utilizava-se o Plano Nacional de Controle de Resíduos Biológicos em Produtos de Origem Animal
(PNCRB), IN/MAPA No 42, de 20 de dezembro de 1999, no qual estava inserido o Programa de Controle de Resíduos em Leite (PCRL) (BRASIL 1999), que tinha como objetivo sistematizar os meios de controle da contaminação desses produtos por resíduos de compostos de uso na agropecuária, bem como de poluentes ambientais (BRASIL 2001), ou seja, esta normativa buscava controlar o uso dos medicamentos, e indiretamente prevenir a contaminação do alimento.

Porém, no ano de 2003, a ANVISA instituiu o Programa Nacional de Análise de Resíduos de Medicamentos Veterinários em Alimentos Expostos ao Consumo (PAMVet), que tem como objetivo detectar os níveis de substâncias químicas em alimentos de origem animal, sujeitos à contaminação por esses resíduos durante a produção. As análises laboratoriais previstas por esse programa se iniciaram com o leite bovino e tinham duração prevista de cinco anos a partir de seu início em 2003 (BRASIL 2003b). As legislações em vigência atualmente encontram-se na Tabela 3.

\section{Impactos causados pelo leite com resíduos de antimicrobianos}

A presença de resíduos no leite de consumo consiste em problema de saúde pública, pois pode levar a problemas de hipersensibilidade, choque anafilático, efeitos tóxicos (ANDERSON et al. 1995) e carcinogênicos. Por exemplo, em gestantes, o uso de nitrofuranos e tetraciclinas podem levar a alterações no desenvolvimento ósseo do feto (PEZZA et al. 2006). Pode haver indução de quadros patológicos, como a anemia crônica causada pelo cloranfenicol, proibido no Brasil desde 2003 (BRASIL 2003a), alterações no equilíbrio da microbiota intestinal, seleção de bactérias resistentes no sistema digestório dos consumidores, multirresistência entre microrganismos através de transferência de plasmídeos e efeitos colaterais secundários (FAGUNDES 1981). A resistência bacteriana aos mais diversos antimicrobianos tem se tornado recorrente e leva a dificuldades no tratamento de enfermidades comuns (ALMEIDA et al. 2003). As reações de hipersensibilidade se manifestam através de urticárias, dermatites, rinites ou asma brônquica e estão mais relacionadas às penicilinas, porém a tetraciclina, estreptomicina e sulfonamidas também podem desencadear essas reações (BRITO \& LANGE 2005).

De acordo com JONES (1999), cerca de 5 a $10 \%$ da população é hipersensível à penicilina e apresentam 
Tabela 2 - Limite Máximo de Resíduo permitidos de diferentes classes de antibióticos em leite bovino cru em alguns países.

Table 2 - Maximum residue limit of different types of antibiotics in raw bovine milk in some countries.

\begin{tabular}{|c|c|c|c|c|c|c|}
\hline Classes & Analitos & Brasil & China & $\begin{array}{l}\text { Estados } \\
\text { Unidos }\end{array}$ & Japão & União Europeia \\
\hline \multirow[t]{6}{*}{ Beta-Lactâmicos } & Penicilina G & 4 & 4 & 5 & 4 & 4 \\
\hline & Penicilina V & 4 & $\ldots$ & $\ldots$ & $\ldots$ & $\ldots$ \\
\hline & Ceftiofur & 100 & 100 & 100 & 100 & 100 \\
\hline & Cloxacilina & 30 & 30 & 10 & 20 & 30 \\
\hline & Oxacilina & 30 & - & - & 30 & 30 \\
\hline & Dicloxacilina & 30 & - & - & 10 & 30 \\
\hline \multirow[t]{4}{*}{ Tetraclicinas } & Clortetraciclina & 100 & 100 & 300 & 100 & 100 \\
\hline & Doxiciclina & 100 & & _ & _ & _ \\
\hline & Tetraciclina & 100 & 100 & 300 & 100 & 100 \\
\hline & Oxitetraciclina & 100 & 100 & 300 & 100 & 100 \\
\hline \multirow[t]{8}{*}{ Quinolonas } & Ácido Oxolínico & - & - & - & - & - \\
\hline & Ácido Nalidíxico & - & - & - & - & _ \\
\hline & Flumequina & 50 & - & - & 100 & 50 \\
\hline & Difloxacina & - & - & - & - & - \\
\hline & Ciprofloxacina & 100 & 100 & - & - & 100 \\
\hline & Enrofloxacina & 100 & 100 & - & 50 & 100 \\
\hline & Norfloxacina & - & - & - & - & - \\
\hline & Sarafloxacina & - & - & - & - & - \\
\hline \multirow[t]{12}{*}{ Sulfonamidas } & Sulfadimetoxina & 100 & 100 & 10 & 20 & 100 \\
\hline & Sulfaquinoxalina & 100 & 100 & _ & 10 & 100 \\
\hline & Sulfadiazina & 100 & 100 & - & 70 & 100 \\
\hline & Sulfatiazol & 100 & 100 & - & 90 & 100 \\
\hline & Sulfapiridina & 100 & 100 & - & 10 & 100 \\
\hline & Sulfametoxazol & 100 & 100 & - & - & 100 \\
\hline & Sulfametazina & 100 & 25 & - & 25 & 100 \\
\hline & Sulfaclorpiridazina & 100 & 100 & - & - & 100 \\
\hline & Sulfizoxazol & 100 & 100 & $\ldots$ & _ & 100 \\
\hline & Sulfadoxina & 100 & 100 & - & $\overline{60}$ & 100 \\
\hline & Sulfamerazina & 100 & 100 & - & - & 100 \\
\hline & Trimetoprim & - & _ & $\ldots$ & 50 & 50 \\
\hline
\end{tabular}

PICININ (2013).

Valores em $\mu \mathrm{g} / \mathrm{Kg}$.

: Valores não especificados.

reações alérgicas ao ingerirem concentrações de até 1,0 ppb dessa substância.

Ainda há os prejuízos aos laticínios, perdendo grandes quantidades de matéria-prima, levando a perdas econômicas. A presença de antimicrobianos residuais noleiteinterferenos processos de fermentação nos quais são utilizadas culturas acidoláticas para produzir queijos, iogurtes e manteiga (WHITE et al. 1993), dificultando a obtenção destes produtos ou ainda alterando sua qualidade. Nos queijos, provoca má dessoragem da coalhada, fermentação indesejada com produção de gás e maturação prejudicada, além de sabor anormal e textura alterada, tornando o produto friável. Na manteiga, inibem a fermentação láctea parcial ou total, induzindo menor produção de diacetil responsável pelo aroma característico do produto (FAGUNDES 2003).

Os antimicrobianos interferem em análises laboratoriais realizadas como rotina em laticínios, como nos testes de fosfatase, peroxidase e redutase.

É importante ressaltar que esses resíduos são altamente resistentes a tratamentos térmicos, tanto a altas quanto a baixas temperaturas (FAGUNDES 1997). Este é o principal ponto crítico de controle de contaminação química do leite, devendo ser monitorada nas plataformas das indústrias de 
Tabela 3 - Legislações em vigência no Brasil visando o controle de resíduos de antimicrobianos no leite bovino. Table 3 - Legislation in force in Brazil aiming at the control of antimicrobial residues in bovine milk.

\begin{tabular}{|c|c|}
\hline LEGISLAÇÃO & EMENTA \\
\hline IN SDA nº42/1999 & $\begin{array}{l}\text { Altera o Plano Nacional de Controle de Resíduos e Contaminantes em Produtos } \\
\text { de Origem Animal - PNCRC/Animal. }\end{array}$ \\
\hline IN SDA nº51/2002 & $\begin{array}{l}\text { Regulamentos Técnicos de Produção, Identidade e Qualidade do Leite tipo A, } \\
\text { do Leite tipo B, do Leite tipo C, do Leite Pasteurizado e do Leite Cru } \\
\text { Refrigerado e o Regulamento Técnico da Coleta de Leite Cru Refrigerado e seu } \\
\text { Transporte a Granel. }\end{array}$ \\
\hline IN SDA n ${ }^{\circ} 9 / 2003$ & $\begin{array}{l}\text { Proíbe o uso de Cloranfenicol e Nitrofuranos e os produtos que contenham estes } \\
\text { princípios ativos para uso veterinário e suscetível de emprego na alimentação } \\
\text { de todos os animais e insetos. }\end{array}$ \\
\hline Anvisa - RDC n²53/2003 & $\begin{array}{l}\text { Institui o Programa Nacional de Análise de Resíduos de Medicamentos } \\
\text { Veterinários em Alimentos Expostos ao Consumo (PAMVet) }\end{array}$ \\
\hline IN SDA n ${ }^{\circ} 11 / 2004$ & $\begin{array}{l}\text { Proíbe o uso da substância Olaquindox como aditivo promotor de crescimento } \\
\text { em animais produtores de alimentos. }\end{array}$ \\
\hline IN SDA n $^{\circ} 35 / 2005$ & $\begin{array}{l}\text { Proíbe o uso de produtos destinados à alimentação animal contendo a substância } \\
\text { química denominada Carbadox. }\end{array}$ \\
\hline IN SDA n²6/2009 & $\begin{array}{l}\text { Regulamento Técnico para fabricação, controle, comercialização e emprego de } \\
\text { produtos antimicrobianos de uso veterinário. Os Anfenicóis, Tetraciclinas, } \\
\text { Beta-Lactâmicos (Benzilpenicilâmicos e Cefalosporinas), Quinolonas } \\
\text { Sulfonamidas sistêmicas são de uso exclusivo em produtos antimicrobianos de } \\
\text { uso veterinário, sendo vedada a sua utilização como aditivos zootécnicos } \\
\text { melhoradores de desempenho ou como conservantes de alimentos para animais. }\end{array}$ \\
\hline Portaria SDA n $396 / 2009$ & $\begin{array}{l}\text { Estabelece responsabilidades das unidades da Secretaria de Defesa } \\
\text { Agropecuária - SDA envolvidas no Subprograma de Investigação do } \\
\text { PNCRC/MAPA. }\end{array}$ \\
\hline IN SDA nº2/2011 & $\begin{array}{l}\text { Regulamento Técnico de Produção, Identidade e Qualidade do Leite tipo A, o } \\
\text { Regulamento Técnico de Identidade e Qualidade de Leite Cru Refrigerado, o } \\
\text { Regulamento Técnico de Identidade e Qualidade de Leite Pasteurizado e o } \\
\text { Regulamento Técnico da Coleta de Leite Cru Refrigerado e seu Transporte a } \\
\text { Granel }\end{array}$ \\
\hline IN SDA n ${ }^{\circ} 14 / 2012$ & $\begin{array}{l}\text { Proíbe o uso das substâncias antimicrobianas "Espiramicina" e "Eritromicina" } \\
\text { com finalidade de aditivo zootécnico melhorador de desempenho na } \\
\text { alimentação animal. }\end{array}$ \\
\hline $\begin{array}{l}\text { Anvisa - Resolução RDC n }{ }^{\circ} \\
42 / 2013\end{array}$ & $\begin{array}{l}\text { Aprova o Regulamento Técnico sobre Limites Máximos de Contaminantes } \\
\text { Inorgânicos em Alimentos. }\end{array}$ \\
\hline $\begin{array}{l}\text { Codex Alimentarius - } \\
\text { CAC/MRL n } 02 / 2014\end{array}$ & $\begin{array}{l}\text { Atualiza os limites máximos de resíduos de produtos de uso veterinário em } \\
\text { alimentos. }\end{array}$ \\
\hline $\begin{array}{l}\text { União Europeia - Decisão }{ }^{0} \\
\qquad 891 / 2014\end{array}$ & $\begin{array}{l}\text { Reconhecimento da equivalência dos planos de controle de resíduos da área } \\
\text { animal de países que não fazem parte da União Europeia. }\end{array}$ \\
\hline
\end{tabular}


laticínios ao se recepcionar a matéria prima (FOLLY \& MACHADO 2001). O processo de pasteurização tem pouco ou nenhum efeito sobre estes resíduos no leite (BRITO \& LANGE 2005).

Conforme a WHO (2001), o problema do leite com resíduos é passível de controle através de vigilância epidemiológica na medicina humana e animal, com foco principalmente na detecção destes contaminantes.

\section{Determinação da presença de resíduos de antimicrobianos no leite}

A Instrução Normativa $n^{\circ} 513$ exige a pesquisa periódica de resíduos de antimicrobianos em leite que não devem ser superiores aos LMR determinados para cada grupo químico específico (ANVISA 2003, CODEX ALIMENTARIUS 2015).

Diversos princípios ativos são permitidos no Brasil para o tratamento da mastite bovina. Assim, as indústrias devem realizar maior número de testes para detectar a presença de resíduos, elevando o custo, principalmente por se tratar de procedimento de rotina (ARAÚJO 2010).

Para a pesquisa de antimicrobianos no leite bovino, primeiramente é realizada triagem (Tabela 4), etapa constituída por testes qualitativos que não exige muito investimento, instrumentos laboratoriais complexos, nem capacitação profissional (HILLERTON et al. 1999, ARAÚJO 2010) e pode ter várias amostras analisadas simultaneamente. Para tanto, o MAPA aprovou e autorizou o uso de vários kits analíticos de detecção de resíduos de antimicrobianos para o controle da presença dessas substâncias em leite, utilizando diferentes princípios de ação e detecção. Sua sensibilidade deve ser superior aos LMR das substâncias a serem detectadas. Estes testes são geralmente baseados na inibição do crescimento, testes imunológicos e enzimáticos com receptores específicos, além de técnicas cromatográficas (FERREIRA et al. 2012).

Preconiza-se que esta triagem seja feita pelas indústrias de laticínios, visto que a legislação

Tabela 4 - Algumas análises usadas como triagem para pesquisa de resíduos de antimicrobianos em leite bovino. Table 4 - Some analyzes used as screening for researching on antimicrobial residues in bovine milk.

\begin{tabular}{|c|c|c|}
\hline Princípio do Teste & Testes e Kits Comerciais & $\begin{array}{c}\text { Classes de Antimicrobianos } \\
\text { Detectadas }\end{array}$ \\
\hline \multirow{4}{*}{$\begin{array}{l}\text { Inibição do crescimento } \\
\text { microbiano }\end{array}$} & $\begin{array}{c}\text { Charm - Test TM } \\
\text { (Charm Science Incorporation, } \\
\text { EUA) }\end{array}$ & $\begin{array}{c}\text { Aminoglicosídeos } \\
\text { Beta-lactâmicos } \\
\text { Macrolídeos } \\
\text { Tetraciclinas } \\
\text { Sulfonamidas } \\
\end{array}$ \\
\hline & $\begin{array}{c}\text { Copan CH ATK }{ }^{\circledR} \\
\text { (Copan Italia Spa, Itália) }\end{array}$ & $\begin{array}{l}\text { Beta-lactâmicos } \\
\text { Tetraciclinas } \\
\text { Sulfonamidas }\end{array}$ \\
\hline & $\begin{array}{c}\text { Delvotest }-\mathrm{P}^{\circledR} \\
\text { (Gist Brocades, Holanda) }\end{array}$ & $\begin{array}{l}\text { Beta-lactâmicos } \\
\text { Tetraciclinas } \\
\text { Sulfonamidas }\end{array}$ \\
\hline & $\begin{array}{c}\text { Delvotest }-\mathrm{SP}^{\circledR} \\
\text { (Gist Brocades, Holanda) }\end{array}$ & $\begin{array}{l}\text { Aminoglicosídeos } \\
\text { Beta-lactâmicos }\end{array}$ \\
\hline \multirow{4}{*}{$\begin{array}{l}\text { Enzyme linked immuno sorbent } \\
\text { assay }\end{array}$} & $\begin{array}{c}\text { Charm SL }- \text { Test TM } \\
\text { (Charm Science Incorporation, } \\
\text { EUA) }\end{array}$ & $\begin{array}{l}\text { Beta-lactâmicos } \\
\text { Tetraciclinas } \\
\text { Sulfonamidas }\end{array}$ \\
\hline & $\begin{array}{l}\text { Cite Probe Gentamicin Test }{ }^{\circledR} \\
\text { (Idexx Laboratories, EUA) }\end{array}$ & Aminoglicosídeos \\
\hline & $\begin{array}{l}\text { Ridascreen chloramphenicol }{ }^{\circledR} \\
\text { (R-Biopharm, Alemanha) }\end{array}$ & Anfenicóis \\
\hline & $\begin{array}{c}\text { Snap beta-lactam Test }{ }^{\circledR} \\
\text { (Idexx Laboratories, EUA) }\end{array}$ & Beta-Lactâmicos \\
\hline
\end{tabular}

FERREIRA et al. (2012). 
estabelece que essa pesquisa seja feita antes do beneficiamento do leite (ARAÚJO 2010).

Os resultados suspeitos ou positivos, indicam que, pelo teste, o LMR foi superado, e portanto a amostra em questão deve passar por método confirmatório que quantifique esse resíduo (BRASIL 1999, ARAÚJO 2010).

A Decisão da Comissão Europeia nº57, de 12 de agosto de 2002, institui que os métodos usados para confirmação devem comprovar a estrutura do princípio ativo do analito. Estes testes geralmente utilizam técnicas de cromatografia e espectrometria de massas (FERREIRA et al. 2012), como por exemplo a Cromatografia Líquida de Alta Eficiência acoplada à Espectrometria de Massas (CLAE-EM) (Tabela 5).

\section{Controle de resíduos de antimicrobianos no leite}

Há a necessidade da difusão de boas práticas veterinárias e agrícolas para a redução dos níveis dessas substâncias no leite (FONSECA \& SANTOS 2007). A implementação de legislações juntamente com um trabalho de educação e monitoramento são de grande valia para controlar a presença dos resíduos no leite, como é o caso do PNCRC (Plano Nacional de Controle de Resíduos e Contaminantes) do MAPA, que no ano de 2014 apontou uma amostra não conforme de um total de 309 amostras analisadas ao longo do período (BRASIL 2015a).

Os resíduos de substâncias químicas no leite têm porta de entrada principalmente na produção primária, mais ainda do que a adulteração. Por isso, é

Tabela 5 - Técnicas de cromatografia para pesquisa confirmatória de resíduos de antimicrobianos em leite bovino.

Table 5 - Chromatography techniques for confirmatory research of antimicrobial residues in bovine milk.

\begin{tabular}{ccc}
\hline Classe de Antibiótico & Tipo de Cromatografia & Detector \\
\hline Aminoglicosídeos & CLAE & $\begin{array}{c}\text { EM/EM } \\
\text { com ionização química à pressão } \\
\text { atmosférica e analisador do tipo } \\
\text { quadrupolo por tempo de vôo }\end{array}$ \\
\hline Anfenicóis & CLAE & EM \\
& DAD \\
\hline
\end{tabular}

Beta-Lactâmicos $\quad$ DAD

CLAE EM/EM

\begin{tabular}{ccc} 
& CLAE & $\begin{array}{c}\text { EM/EM } \\
\text { com ionização por Eletrospray (ESI) e } \\
\text { analisador do tipo triplo quadrupolo }\end{array}$ \\
\hline Macrolídeos & CLAE & EM \\
\hline
\end{tabular}

UV

DAD

Tetraciclinas

CLAE

$\mathrm{EM} / \mathrm{EM}$

com ionização por Eletrospray(ESI) e analisador do tipo triplo quadrupolo

RF

Sulfonamidas CLAE

DAD

FERREIRA et al. (2012).

CLAE: Cromatografia Líquida de Alta Eficiência; DAD: Detector de Arranjo de Diodos; EM: Espectrometria de Massas Simples Quadrupolo; EM/EM: Espectrometria de Massas Sequencial; RF: Detector de Fluorescência; UV: Detector de Absorção na Luz Ultravioleta. 
necessária a elucidação dos produtores sobre os fatores que levam aos resíduos no leite e como preveni-los, trabalhando com a educação em relação à aplicação de antibioticoterapia, evitando que os resíduos dessas drogas cheguem aos produtos consumidos pelos humanos.

Como controle, os animais tratados devem ser identificados, visto o tamanho dos rebanhos de gado leiteiro e os diferentes ordenhadores. Além disso, o período de descarte deve ser de conhecimento de todos os trabalhadores da propriedade. As vacas tratadas devem sempre ser ordenhadas por último, evitando a contaminação do leite do rebanho (SILVA et al. 2013).

Devem-se manter anotações de todos os tratamentos empregados, incluindo a identificação do animal, a data e motivo do tratamento, o medicamento usado (respeitando a dosagem recomendada), quem administrou o tratamento e o período de descarte, observando-se que este período não é o mesmo para todas os princípios ativos. Ainda, o descarte deve ser feito de maneira a não contaminar o meio ambiente, ou seja, em estações de tratamento de efluentes.

Para o controle efetivo de resíduos de antimicrobianos no leite é necessária a tomada de medidas preventivas conjuntas nos princípios da obtenção do leite que irão dificultar ou mesmo sanar a contaminação por medicamentos. A principal causa de ocorrência de produtos de uso veterinário no leite, como antimicrobianos, é o tratamento de infecções apresentadas na matriz leiteira, principalmente a mastite, que pode ser prevenida com a limpeza dos tetos (água e sabão), a aplicação de saneantes antes e após a ordenha e a alimentação do animal depois da ordenha (mantendo a vaca de pé, evitando que os tetos com os canais (esfíncter) abertos entrem em contato com o chão, favorecendo a contaminação), ou seja, manejo correto da matriz dificultará o aparecimento de mastites, evitando o tratamento de possíveis infecções por antimicrobianos (COSTA 2005, FONSECA \& SANTOS 2007).

\section{CONCLUSÃO}

Produzir e processar leite de alta qualidade é benefício para os consumidores, mas também para produtores e indústria, pois a confiança de quem consome o produto é necessária para manter a competitividade na cadeia produtiva a médio e longo prazos. Dessa maneira, todos os procedimentos em relação à higiene de produção, não adulteração e respeito aos períodos de carência de produtos de uso veterinário lícitos na produção animal de bovinocultura leiteira asseguram que o leite que sai da propriedade seja de alta qualidade e livre de perigos à saúde humana.

\section{REFERÊNCIAS}

ALMEIDA LP et al. 2003. Resíduos de Antibióticos em Leite de Propriedades Rurais da Região de Uberlândia MG. Bioscience Journal 19: 83-87.

ANDERSON KL et al.1995. Potential for oxitetracicline administration by three routes to cause milk residues in lactation cows, as detected by radioimmunoassay (Charm II) and high-performance liquid chromatography test methods. American Journal of Veterinary Research 56: 7077.

ANTUNES LAF. 1985. Antibióticos e seu uso em alimentos. Revista Higiene Alimentar 4: 89-95.

ANVISA - Agência Nacional de Vigilância Sanitária. 2003. Programa Nacional de Análise de Resíduos de Medicamentos Veterinários em Alimentos Expostos ao Consumo - PAMVet. Brasília. Disponível em: $<$ http://www. anvisa.gov.br/alimentos/pamvet/pamvet.pdf $>$. Acesso em: 01 ago. 2015.

ARAÚJO MMP. 2010. Validação de métodos imunoenzimáticos para determinação de resíduos de antimicrobianos no leite. Dissertação (Mestrado em Ciência Animal). Belo Horizonte: UFMG . 46p.

BACHA WJ \& BACHA LM. 2000. Color atlas of veterinary histology. 2.ed. Philadelphia: Lippincott Williams \& Wilkins. 318p.

BARROS GMS et al. 2001. Pesquisa de resíduos de antibióticos em leite pasteurizado tipo $\mathrm{C}$, comercializado na cidade de Salvador. Revista Brasileira de Saúde e Produção Animal 2: 69-73.

BORGES GT et al. 2000. Ocorrência de resíduos de antibióticos em leite pasteurizado integral e padronizado produzido e comercializado no Estado de Goiás. Ciência Animal Brasileira 1: 59-63.

BRASIL. 1980. Ministério da Agricultura, Pecuária e Abastecimento. Regulamento da Inspeção Industrial e Sanitária de Produtos de Origem Animal (Aprovado pelo decreto n. 30690, de 20.03.52, alterado pelo decreto n. 1255, de 25.06.52). R.I.I.S.P.O.A, Ministério da Agricultura, Brasília. 66p

BRASIL. 1999. Ministério da Agricultura, Pecuária e Abastecimento. Instrução Normativa n. 42, de 20 de dezembro de 1999, que altera o Plano Nacional de Controle de Resíduos em Produtos de Origem Animal. Diário Oficial da União, Brasília, DF, 22 dez. 1999. Seção 1, página 13. BRASIL. 2001. Agência Nacional de Vigilância Sanitária. Medicamentos veterinários e saúde pública: uma proposta de ação para a Anvisa. São Paulo: Anvisa. 19p.

BRASIL. 2002. Ministério da Agricultura, Pecuária e 
Abastecimento. Instrução Normativa n. 51, de 18 de outubro de 2002. Aprova os regulamentos técnicos de produção, identidade e qualidade do leite tipo A, do leite tipo B, do leite tipo $\mathrm{C}$, do leite pasteurizado e do leite cru refrigerado e o regulamento técnico da coleta de leite cru refrigerado e seu transporte e granel. Diário Oficial da União. Brasília, DF, 18 set. 2002.

BRASIL. 2003a. Instrução Normativa IN no 09, de 27 de junho de 2003. Pró́be a fabricação, a manipulação, o fracionamento, a comercialização, a importação e o uso dos princípios ativos cloranfenicol nitrofuranos e os produtos que contenham estes princípios ativos, para uso veterinário e suscetível de emprego na alimentação de todos os animais e insetos. Diário Oficial da União, Brasília, 27 jun. 2003.

BRASIL. 2003b. Resolução RDC $n^{\circ} 253$, de 16 de setembro de 2003. Cria Programa de Análise de Resíduos de Medicamentos Veterinários em Alimentos de Origem Animal - PAMVet. Diário Oficial da União, Brasília, p. 9091, 18 set. 2003.

BRASIL. 2011. Ministério da Agricultura, Pecuária e Abastecimento. Instrução Normativa $\mathrm{n}^{\circ} 62$, de 29 de Dezembro de 2011. Regulamento Técnico de Produção, Identidade e Qualidade do Leite Cru Refrigerado (Revogados os Anexos II e III da Instrução Normativa $n^{\circ}$ 51, de 18 de setembro de 2002). Diário Oficial da União. Brasília, DF.

BRASIL. 2015a. Ministério da Agricultura, Pecuária e Abastecimento. Portaria SDA No 22, de 07 de abril de 2015. Divulga os resultados do subprograma de monitoramento e do subprograma exploratório do Plano Nacional de Controle de Resíduos e Contaminantes - PNCRC do ano 2014, das cadeias de carnes bovina, suína, caprina, ovina, equina, de ave e de avestruz e cadeias de leite, ovos, mel e pescado. Diário Oficial da União. Brasília, DF, 10 abr. 2015.

BRASIL. 2015b. Ministério da Agricultura, Pecuária e Abastecimento. Sislegis. Disponível em: <http:// sistemasweb.agricultura.gov.br/sislegis/action/detalhaAto. do method $=$ abreLegislacaoFederal\& chave $=50674 \&$ tipoL egis $=\mathrm{A}>$. Acesso em: 14 ago. 2015.

BRITO JRF \& BRITO MAVP. 1997. Conceitos básicos da qualidade do leite. Leite Brasil, set. 1997. Disponível em: $<$ http:// www.leitebrasil.org.br >. Acesso em: 20 ago. 2015. BRITO MAVP \& LANGE CC. 2005. Resíduos de Antibióticos no leite. Juiz de Fora: EMBRAPA Gado de Leite. 3p. (Comunicado Técnico, 44).

CODEX ALIMENTARIUS. 2015. Veterinary Drug Residues in Food. Disponível em: <http://faostat.fao.org/ faostat/vetdrugs/jsp/>. Acesso em: 01 ago. 2015.

COSTA EO. 2005. Mastite: os seus prejuízos em números. Revista Balde Branco. Disponível: <http://www. bichoonline.com.br/artigos/bb0003.htm\#top>. Acesso em: 30 jul. 2015.

COSTA EO. 1996. Resíduos de antibióticos no leite: um risco à saúde do consumidor. Revista Higiene Alimentar
10: $15-17$.

COSTA RG et al. 2009. Influência do alimento na produção e qualidade do leite de cabra. Revista Brasileira de Zootecnia 38: 307-321.

COVA WG. 1984. Prática sensitive de detecção de penicilina no leite. Revista Higiene Alimentar 3: 207-211.

DÍAZ-CRUZ MS \& BARCELÓ D. 2007. Recent advances in LC-MS residue analysis of veterinary medicines in the terrestrial environment. TrAC Trends in Analytical Chemistry 26: 637-646.

DÜRR JW. 2004. Programa Nacional de Melhoria da Qualidade do Leite: uma oportunidade única. In: DÜRR JW et al. (Ed.). O compromisso com a qualidade do leite no Brasil. Passo Fundo: UPF. p.38-55.

FAGUNDES CM. 1978. Persistência de antibióticos no leite bovino em condições experimentais e prevalência nos leites tipo "B" e "C" consumidos em Belo Horizonte. Dissertação (Mestrado em Medicina Veterinária). Belo Horizonte: UFMG. 48p.

FAGUNDES CM. 1981. Persistência de antibióticos no leite bovino e em condições experimentais. Revista do Instituto de Laticínios Cândido Tostes 36: 27-30.

FAGUNDES CM. 1997. Inibidores e controle de qualidade do leite. Pelotas: UFPEL. 128p.

FAGUNDES H. 2003. Ocorrência de resíduos de antimicrobianos utilizados no tratamento de interrupção de lactação no início da lactação subsequente em animais com período seco recomendado. Dissertação (Mestrado em Qualidade Produtiva Animal). Pirassununga: USP. 76p.

FERREIRA RG et al. 2012. Panorama da ocorrência de resíduos de medicamentos veterinários em leite no Brasil. Segurança Alimentar e Nutricional 19: 30-49.

FOLLY MM \& MACHADO SCA. 2001. Determinação de resíduos de antibióticos, utilizando-se métodos de inibição microbiana, enzimático e imunoensaios no leite pasteurizado comercializado na região norte do estado do Rio de Janeiro, Brasil. Ciência Rural 31: 95-98.

FONSECA LFL \& SANTOS MV. 2007. Estratégias para controle de mastites e melhoria da qualidade do leite. Barueri: Manole. 314p.

FRANDSON RD et al. 2014. Anatomia e Fisiologia das Glândulas Mamárias. In: FRANDSON RD et al. Anatomia e Fisiologia dos animais de Fazenda. 7.ed. Rio de Janeiro: Guanabara Koogan. p.359-368.

GUSTAFSON RH. 1986. Agricultural Uses of Antibiotics (ACS Symposium Series). In: MOATS WA (Ed). American Chemical Society: Washington. Cap. 7.

HILLERTON JE et al. 1999. Detection of antimicrobial substances in individual cow and quarter milk samples using Delvotest microbial inhibitor tests. Journal of Dairy Science 82: 704-711.

IBGE - Instituto Brasileiro de Geografia e Estatística. 2015. Indicadores IBGE: Estatística da Produção Pecuária. Disponível em: <http://www.ibge.gov.br/home/estatistica/ indicadores/agropecuaria/producaoagropecuaria/abate- 
leite-couro-ovos_201501_publ_completa.pdf $>$. Acesso em: 10 ago. 2015 .

JONES GM. 1999. On-farm tests for drug residues in milk. Petersburg: Virginia State University. 6p.

JONES GM \& SEYMOUR EH. 1988. Cowside antibiotic residue testing. Journal of Dairy Science 71: 1691-1699.

KISER JS. 1984. Subtherapeutic uses of antibiotics and sulfonamides in animal agriculture. In: STEELE JH et al. Antibiotics, sulfonamides, and public health. Boca Raton: CRC Press. pp.81-107.

MITCHELL JM et al. 1998. Antimicrobial drug residues in milk and meat: causes, concerns, prevalence, regulations, tests, and tests performance. Journal of Food Protection 61: 742-756.

OLIVEIRA JS et al. 2005. Uso de Aditivos na Nutrição de Ruminantes. Revista Electrónica de Veterinaria 6: 1-23.

PALERMO-NETO J. 2007. O problema do uso inadequado de antibióticos na produção de suínos. Acta Scientiae Veterinariae 35: 199-208.

PALERMO-NETO J \& ALMEIDA RT. 2014. Antimicrobianos como aditivos em animais de produção. In: SPINOZA HS et al. Farmacologia aplicada à medicina veterinária. Rio de Janeiro: Guanabara Koogan. p.608-629. PEZZA L et. al. 2006. Determinação simultânea de resíduos de cloranfenicol, tianfenicol e florfenicol em leite bovino por cromatografia eletrocinéticas micelar. Química Nova 29: 926-931.

PICININ LCA. 2013. Resíduos de produtos de uso veterinário e contaminantes em leite. Tese (Doutorado em Ciência dos Alimentos). Florianópolis: UFSC. 172p.

RAIA JR RB. 2001. Influência da mastite na ocorrência de resíduos de antimicrobianos no leite. Dissertação (Mestrado em Toxicologia e Análises Toxicológicas). São Paulo: USP. 87p.

RUBEZ J. 2003. O leite nos últimos 10 anos. Disponível em: <http://www.leitebrasil.org.br/artigos/jrubez_093. htm>. Acesso em: 17 jul. 2015.

SILVA DP et al. 2013. Resíduos de antibiótico em leite: prevalência, danos à saúde e prejuízos na indústria de laticínios. Evidência 13: 127-152.

SPINOSA HS et al. 2014. Farmacologia Aplicada a Medicina Veterinária. Rio de Janeiro: Guanabara Koogan. $824 \mathrm{p}$.

SPINOSA HS \& TÁRRAGA KM. 2014. Considerações Gerais sobre os Antimicrobianos. In: SPINOSA HS et al. Farmacologia Aplicada a Medicina Veterinária. 5.ed. Rio de Janeiro: Guanabara Koogan. p.409-417.

THIELE-BRUHN S. 2003. Pharmaceutical antibiotic compounds in soils - a review. Journal of Plant Nutrition and Soil Science 166: 145-167.

USDA. United States Department of Agriculture. 2011. World Agricultural Supply and Demand Estimates, n.501, December 9.

VEISSEYRE R. 1998. Lactologia técnica: composición recogida, tratamento y transformacio de la leche. Zaragoza:
Acribia. p.1-10.

VIEIRA JFS. 2010. Estudo retrospectivo sobre agentes de mastites e sua sensibilidade a antimicrobianos em explorações de Montemor-o-Velho. Dissertação (Mestrado em Medicina Veterinária. Lisboa: UTL. 114p.

WHITE CR et al. 1993. Optimization of a liquid chromatographic method for determination of oxytetracycline, tetracycline, and chlortetracycline in milk. Journal of AOAC International 76: 548-554.

WHO - World Health Organization. 2001. Overcoming Antimicrobial Resistance. World Health Report on Infectious Diseases 2000. Geneva. p.1-21. 